\title{
Effects of rewarded and nonrewarded prereversal training on discrimination reversal learning in rats
}

DAVID A. STEVENS AND LAURENCE D. FECHTER ${ }^{2}$

CLARK UNIVERSITY

Rats given nonrewarded experience with the former $S+$ after mastery of a visual discrimination learned the reversal of the discrimination with fewer errors than Ss given rewarded prereversal experience with the former $S$-. This finding was similar to those previously found with monkeys.

Discrimination reversal learning involves learning to avoid the former S+ and learning to approach the former S-. The purpose of the present study was to determine the relative importance of these two factors in discrimination reversal learning in the rat. The Ss were trained to mastery of a discrimination, given either rewarded experience with the former $\mathrm{S}-$ or nonrewarded experience with the former $\mathrm{S}+$, and then given discrimination reversal training.

Subjects

The Ss were 20 male Sprague-Dawley rats with a mean body weight of $300 \mathrm{~g}$ at the beginning of the experiment.

\section{Apparafus}

A trapezoidal discrimination box was used. It was 5 in. high, 27 in. long, 6 in. wide at one end, 12 in. wide at the other end, and had a Plexiglas cover and a grid floor. A guillotine door 7 in. from the narrow end provided a start box. Openings 3 in. sq. and 6 in. apart were located in the wall of the wide end. A 6 in. partition separated these openings and there were guillotine doors between the end of the partition and the walls of the apparatus. A sliding panel with three swinging doors, faced with stimulus cards leading to separate goal boxes, was located immediately behind the wide end. The doors were placed so that by sliding the panel, either the left and center or center and right doors would match the two openings in the wall of the discrimination box. A water fount, hidden from direct view, was located in the center goal box. A removable barrier could be attached to the partition and swung against the left or right wall near the start box door when it was necessary to permit $S$ to see and respond to only one stimulus.

\section{Procedure}

All Ss were adapted to and maintained on a $23 \mathrm{~h}$ $50 \mathrm{~min}$ water deprivation schedule. For pretraining, the barrier was installed so that only one goal box was available to $S$, and gray stimulus cards were attached to the goal box doors. Each $S$ was allowed to explore the apparatus for $10 \mathrm{~min}$ with all doors open and the water fount removed. Then, 20 rewarded trials were given, during which the goal box door was gradually lowered from a fully open to closed position. In this and subsequent phases of the experiment, 10 trials a day were given, Gellerman sequences were used to determine the position of the stimuli, and a reward of $3 \mathrm{sec}$ of drinking was used.

For acquisition training, the barrier was removed, giving $S$ access to both doors. White $(S+)$ and black (S-) cards were attached to the doors and Ss were trained until a criterion of nine correct choices within a daily session was met. As $S$ approached either stimulus, the guillotine doors between the partition and walls were lowered to prevent correction of response. As Ss met the criterion they were alternately assigned to receive either rewarded or nonrewarded prereversal experience. The former Ss were given 20 trials of rewarded experience with the black stimulus (formerly $\mathrm{S}-$ ) and the latter Ss were given 20 trials of nonrewarded experience with the white stimulus (formerly $\mathrm{S}+$ ). For this phase the barrier was installed so that only that stimulus to which $S$ was being trained was available. After prereversal training, reversal discrimination training was given. The black stimulus was now $\mathrm{S}+$ and the white stimulus was S-. Training continued until the criterion of nine correct responses within a daily session was met. Results and Discussion

The mean errors to criterion in the acquisition of the original discrimination were $\mathbf{5 1 . 5}$ for Ss subsequently given rewarded prereversal training, and 49.6 for Ss subsequently given nonrewarded prereversal training. Figure 1 shows the reversal learning curves for the two groups. For this graph, scores of $100 \%$ correct were assigned to Ss after the criterion was met. The performance of the two groups was similar for the first four days, after which Ss given nonrewarded prereversal training gradually emerged as the more rapid learners. The mean number of errors to criterion for reversal learning was 91.1 for Ss given rewarded training and 54.0 for Ss given nonrewarded training. A $t$ test indicated that the groups differed significantly $(t=2.80, d f=18, p<.02)$.

Since nonrewarded training was superior to rewarded training, the present findings support theoretical positions that stress the importance of inhibition (Harlow \& Hicks, 1957) or the acquisition of avoidance tendencies (D'Amato \& Jagoda, 1961) in discrimination learning. The findings are also of interest 


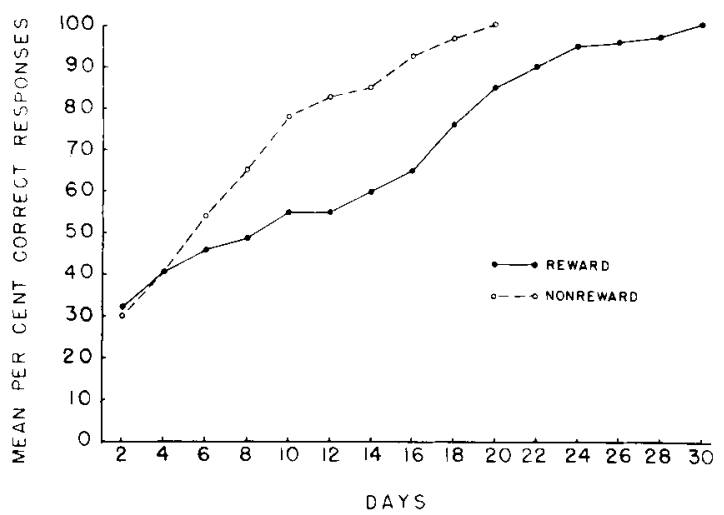

Fig. 1. Discrimination reversal learning curves for groups given either rewarded prereversal training to the former $S$ - or nonrewarded prereversal training to the former $\mathrm{S}+$.

within a comparative context. When the effectiveness of rewarded and nonrewarded prereversal training was compared in monkeys, results in the same direction as the present findings were obtained (Cross \& Brown, 1965; Cross, Fickling, Carpenter, \& Brown, 1964). Also, a greater tendency to avoid $S-$ than to approach St following mastery of a discrimination has been found in both monkeys (Riopelle, 1955) and rats when positive reinforcement was used (Stevens \& Fechter, in press). In contrast, monkeys and rats differ in the relative effectiveness of initial reward and nonreward in the acquisition of a discrimination. Monkeys discriminate more accurately following experience with $S-$ than following experience with $S_{+}$
(Harlow \& Hicks, 1957; Moss \& Harlow, 1947), but rats discriminate visual stimuli more accurately following experience with S+ than with S- (Vaughter, Tyer, \& Halcomb, 1966). Taken together with the present results, these findings suggest that differences between monkeys and rats in the relative effectiveness of rewarded and nonrewarded training may be found only when the effects are measured relatively early in training.

\section{References}

CROSS, H. A., \& BROWN, L. T. Discrimination reversal learning in squirrel monkeys as a function of number of acquisition trials and prereversal experience. J. comp. physiol. Psychol., 1965, 59, 429-431.

CROSS, H. A., FICKLING, R. M., CARPENTER, J. B., \& BROWN, L. T. Discrimination reversal performance in squirrel monkeys as a function prereversal experience and overlearning. Psychon. Sci., 1964, 1, 353354.

D'AMATO, M. A., \& JAGODA, H. Analysis of the role of overlearning in discrimination reversal. J. exp. Psychol., 1961, 61, 45-60.

HARLOW, H. F., \& HICKS, L. H. Discrimination learning theory: uniprocess vs. duoprocess. Psychol. Rev., 1957, 64, 104-109.

MOSS, E. M., \& HARLOW, H. F. The role of reward in discrimination learning in monkeys. J. comp. Psychol., 1947, 40, 333-342.

RIOPELLE, A. J. Learning sets from minimum stimuli. J. exp. Psychol., $1955,49,28-32$.

STEVENS, D. A., \& FECHTER, L. D. Relative strengths of approach and avoidance tendencies in discrimination learning of rats under two types of reinforcement. $J$. exp. Psychol., in press.

VAUGHTER, R. M., TYER, Z. E., \& HALCOMB, C. G. Discrimination performance in deprived and nondeprived rats as a function prediscrimination information. Psychon. Sci., 1966, 5, 199-200.

Notes

1. Supported by NSF/URP Grant GY-116.

2. Now at Kent State University. 